\title{
Experimental study of a waste heat recovery system for supplemental heaters
}

\author{
E. Y. Tanbour, R. Al-Waked \& M. F. Alzoubi \\ Prince Mohammad Bin Fahd University, College of Engineering, \\ Department of Mechanical Engineering, Kingdom of Saudi Arabia
}

\begin{abstract}
Energy conservation in supplemental heaters using a heat recovery heat exchanger is the subject of this paper. A waste-heat-recovery heat exchanger is developed for supplemental heaters (natural gas-fired fireplaces). Using experimental tools, the effectiveness of a condensing heat recovery system on capturing majority of waste heat is studied. The goal is to explore an economically feasible and a manufacturable heat exchanger that recovers waste heat in such supplemental heaters. The research has shown viable compact heat exchanger designs that significantly reduce the fuel consumption by the heater.

Keywords: efficient heating, compact heat exchangers, waste heat recovery, supplemental heaters, gas-fired fireplaces.
\end{abstract}

\section{Introduction}

Energy conservation and management for different applications has been the subject of several studies in the past years and it continues to be an important research topic. This is due to the limited energy resources and energy price from one side and the environmental issues from the other side. Using exhaust flue gas as a heat recovery source is a common approach and it has been an essential part of steam power plants. While its primary purpose is to transfer exhaust gas heat to steam, an important secondary function is to reduce emissions from combustion exhaust [1].

Mihelic-Bodanic and Budin [2] presented an energy optimization for production of a thermoplastic material, using boiler flue gases, which leads to saving about $8 \%$ on the fuel consumption. Maksimov et al. [3] studied the possibility of using exhaust gas in power plants to generate steam for oil 
processing in refineries. Fehrm et al. [4] reported a study on exhaust air heat recovery for warming the buildings in Sweden and Germany. Other examples of heat recovery from exhaust gas are in textile drying [6], heating automobiles [7], coffee roasting [8], road maintenance [9] and paper machines [10].

Using heat exchangers for recovering waste heat has received considerable attention [11-15]. Soylemez [15] reported a thermo-economic optimization analysis that can estimate the optimum heat exchanger area for energy recovery application. A survey conducted by University of Iowa [16] provided an indication of what is available on the American and Canadian markets in terms of waste heat recovery methods and the state-of-the-art in the area. The survey found 17 US patents on this topic.

The goal of this paper is to explore an economically feasible and a manufacturable heat exchanger that recovers waste heat from the exhaust gases of a natural gas-fired supplemental heating unit (fire place, stove). This is achieved by presenting basic analysis for the heat exchanger, describing a prototype heat exchanger and examining the experimental procedures used to test the prototype heat exchanger. The experimental results are acquired for three different test conditions in an attempt to define the importance of the various factors that affect the heat exchanger performance.

\section{Governing equations}

The conventional heat exchanger analysis is based on the effectiveness method [18]. In the investigated heat exchanger, the exhaust gas flows through three passes, while the room air flows through only one pass. The three exhaust-gas passes are modelled by three separated cross-flow heat exchangers as shown in Fig. 1. Each heat exchanger is modelled and the relations for the heat exchangers are solved simultaneously to obtain the final room-air and exhaust-gas outlet temperatures [17].

Heat exchanger 1 (first pass):

$$
q_{1}=C_{e}\left(T_{e 2}-T_{e o}\right)=C_{a}\left(T_{a 1}-T_{a i}\right)=\varepsilon_{1} C_{\min }\left(T_{e 2}-T_{a i}\right)
$$

Heat exchanger 2 (second pass):

$$
q_{2}=C_{e}\left(T_{e 1}-T_{e 2}\right)=C_{a}\left(T_{a 2}-T_{a 1}\right)=\varepsilon_{2} C_{\min }\left(T_{e 1}-T_{a 1}\right)
$$

Heat exchanger 3 (third pass):

$$
q_{3}=C_{e}\left(T_{e i}-T_{e 1}\right)=C_{a}\left(T_{a o}-T_{a 2}\right)=\varepsilon_{3} C_{\min }\left(T_{e i}-T_{a o}\right)
$$

Overall heat exchanger:

$$
q_{3}=C_{e}\left(T_{e i}-T_{e o}\right)=C_{a}\left(T_{a o}-T_{a i}\right)=\varepsilon C_{\min }\left(T_{e i}-T_{a o}\right)
$$

For a cross-flow heat exchanger with the fluid having $C_{\max }$ is mixed and the fluid having $C_{\min }$ is unmixed, the heat exchanger effectiveness $(\varepsilon)$ is: 


$$
\varepsilon=\frac{1}{R}\left(1-e^{-\left\{-R\left[1-e^{-N T U}\right]\right\}}\right)
$$

where,

$$
\begin{gathered}
C_{\text {min }}=\min \left[\dot{m}_{a} C_{p a}, \dot{m}_{e} C_{p e}\right] \\
C_{\text {max }}=\max \left[\dot{m}_{a} C_{p a}, \dot{m}_{e} C_{p e}\right] \\
R=\frac{C_{\text {min }}}{C_{\max }} \\
N T U=\frac{U A_{s}}{C_{\min }}
\end{gathered}
$$

The exhaust-gas volumetric flow rate for the forced combustion air case is based on a mass balance, namely:

$$
\rho_{n g} Q_{n g}+\rho_{c a} Q_{c a}=\rho_{e} Q_{e}
$$

where the densities of the natural gas and combustion air, $\rho_{n g}$ and $\rho_{c a}$, are evaluated at the room-air inlet temperature, and the density of the exhaust gas, $\rho_{e}$, is evaluated at the exhaust-gas outlet temperature.

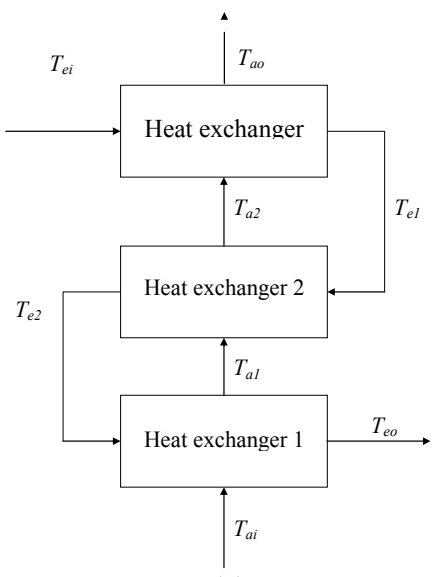

(a)

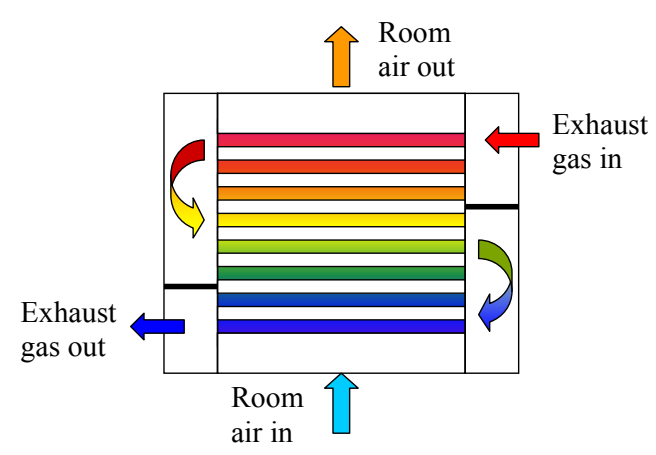

(b)

Figure 1: $\quad$ Schematics of (a) Three passage heat exchanger model, (b) Airflow through the heat exchanger. 


\section{Experiment setup}

\subsection{Prototype heat exchanger}

The prototype heat exchanger, shown in Fig. 2, has a width of $508 \mathrm{~mm}$, a height of $559 \mathrm{~mm}$, and a depth of $127 \mathrm{~mm}$. Contained within the prototype are 19 finned tubes that served to transport the exhaust gases through the heat exchanger. The exhaust gas made three passes through the heat exchanger. For the first and second passes, the exhaust gas passes through six tubes per pass. For the third pass, the exhaust gas passes through seven tubes. Each tube has a length of $35.6 \mathrm{~mm}$, an outer diameter of $16 \mathrm{~mm}$, a wall thickness of $0.9 \mathrm{~mm}$, and contains approximately 370 annular fins per tube. Each fin has a height of 9.5 $\mathrm{mm}$, a thickness of $0.5 \mathrm{~mm}$, and a spacing of $3.2 \mathrm{~mm}$. The exhaust gas travels through the finned tubes into the first manifold located at the top of the heat exchanger. The gas then travels through a second pass of tubes through the heat exchanger into a second manifold on the opposite side. Finally, the gas passes through a third set of tubes at the bottom of the heat exchanger and exits out the exhaust pipe as shown in Fig 1. The exhaust gas is induced into the tubes at a flow rate of $11.6 \mathrm{~L} / \mathrm{s}$ by a fan located at the heat exchanger exit. The 19 finned tubes are parallel to each other and have staggered configuration. The fins are made of carbon steel and are attached to the tubes using interference fit. Air at room temperature is used to cool the exhaust gas and enters the heat exchanger from the bottom and exits at the top. Two blowers located at the bottom of the heat exchanger have the capability to move a total of about $141.6 \mathrm{~L} / \mathrm{s}$ of air over the finned tubes.

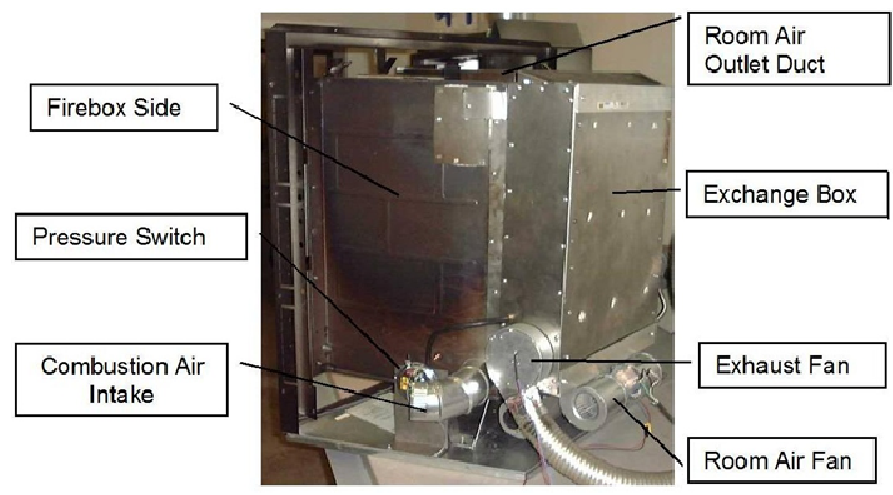

Figure 2: General view of the experimental setup of the prototype heat exchanger.

\subsection{Investigated experiments}

The waste heat recovery system consists of a finned-tube heat exchanger attached to the back of the fireplace. The heat exchanger contains an array of tubes through which the exhaust gas flows. Air flowing over the exhaust tubes is 
used to recover heat from the exhaust gas. Three sets of experiments shown in Fig. 3 were used to examine the different contributions of the heat transfer to the room air: (1) normal operating mode, (2) cold exhaust gas, and (3) isolated heat exchanger.

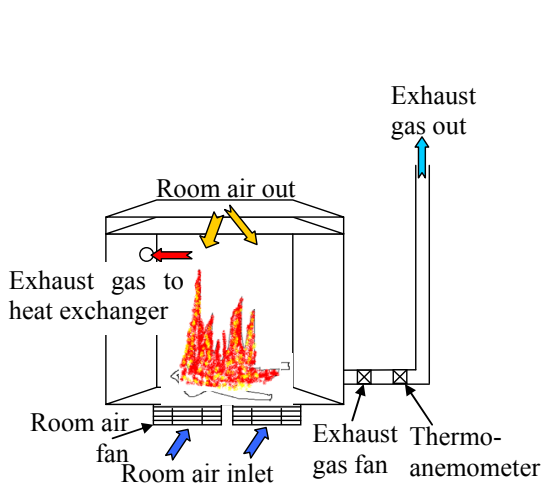

(a)

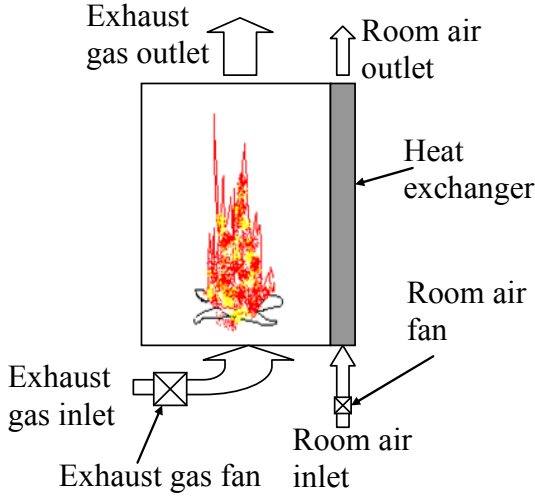

(c)

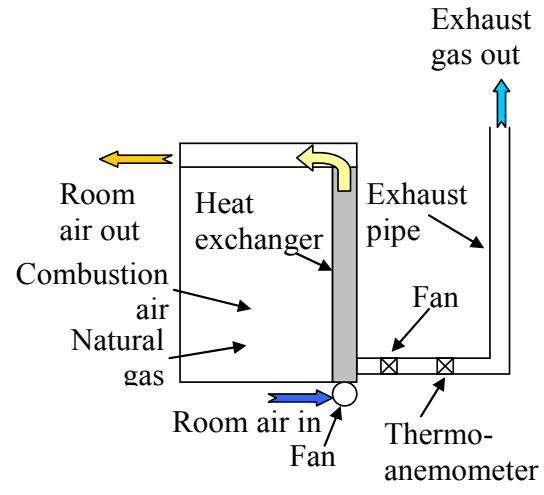

(b)

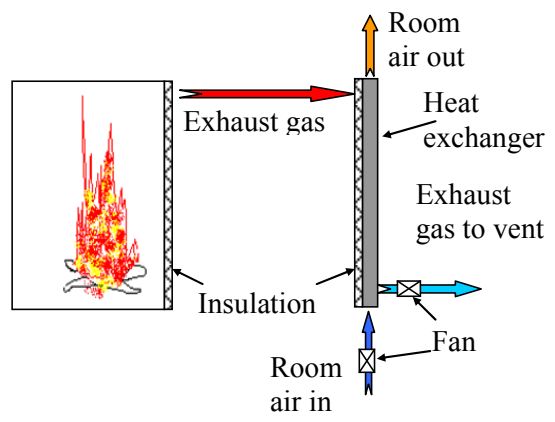

(d)

Figure 3: General view of the experimental setup: (a) front view - normal operating mode, (b) side view - normal operating mode, (c) cold exhaust gas, (d) isolated heat exchanger.

In the normal operating setup, the heat exchanger is attached to the back of the fireplace. The exhaust gas flows into the heat exchanger from the top of the heat exchanger and flows out of the heat exchanger from the bottom in the tube side of the heat exchanger. The room air flows outside of the tubes from the bottom to the top of the heat exchanger. Combustion exhaust air is induced by an exhaust fan through the openings located at the bottom of the fireplace. Experiments are conducted under induced and forced exhaust air flows to check the influence of the different configurations on producing the exhaust-air flow.

For the cold exhaust gas setup, the heat exchanger is attached to the back of the fireplace and the exhaust gas is not allowed to pass through the heat 
exchanger but flows directly to the vent. The room air flows from the bottom to the top of the heat exchanger over the tubes and fins of the heat exchanger. Because the exhaust-gas temperature exceeds the operating temperature of the exhaust fan in this experiment, the exhaust fan is used to force the combustion air into the fireplace air instead of inducing the combustion air. This experiment is used to examine the amount of heat transferred by radiation and convection from the firebox wall.

In the Isolated heat exchanger setup, the heat exchanger is insulated from the fireplace. The exhaust gas and room air pass through the heat exchanger in the same way as for the normal operating mode. The firebox wall and heat exchanger wall on the fireplace side are insulated to minimize the heat loss and the possible heat transfer between them. This experiment is used to examine the direct heat transfer from the exhaust gas to the room air.

\subsection{Instrumentation}

Fluid and surface temperatures at different locations of were measured by thermocouples and recorded using an OMEGA automatic data acquisition system. A total of 27 OMEGA Type-K thermocouples were installed to measure temperatures at various points. The thermocouples have an accuracy of 0.4 to $0.75 \%$ by design. All thermocouples were connected to an OMEGA TempScan data acquisition unit that utilizes the OMEGA TempView software to process the temperature readings and record the temperature readings to a spreadsheet every $30 \mathrm{sec}$. All surface mounted thermocouples are insulated from the surrounding to ensure an accurate measurement for the surface temperature. Thermocouples that measure the room-air or exhaust-gas temperatures were installed in the main stream of the flow and did not touch any surface. The thermocouple used to measure the exhaust-gas inlet temperature was carefully placed inside the first manifold, where the thermocouple cannot receive radiation directly from the fire to ensure the accuracy of the measurement.

The natural-gas flow rate was measured and controlled by an AALBRG mass flow-meter/controller. This meter provides a natural-gas flow ranging from 80 to $120 \%$ with $100 \%$ corresponding to a flow rate of $0.33 \mathrm{~L} / \mathrm{s}$. A variable speed centrifugal fan made by EBM was used to provide the exhaust gas flow. The exhaust-gas volumetric flow rate can be adjusted by changing the voltage applied to the fan. The working voltage for the exhaust fan, Vf, ranges from 8 to $15 \mathrm{~V}$ DC. The exhaust gas flow rate was measured by an Extech thermoanemometer, which was installed downstream to the exhaust-gas fan. The anemometer has an accuracy of $\pm 3 \%$ of reading. A constant speed room-air blower was used to circulate the room air over the tubes and fins of the heat exchanger. The room-air blower is a TWIN cross flow blower made by EBM and it was operated at $115 \mathrm{Volt} / 60 \mathrm{~Hz} \mathrm{AC}$ to provide a $94.4 \mathrm{~L} / \mathrm{s}$ constant roomair flow at no load. An approximate measurement of the room air flow rate is obtained using a handheld flow meter at the room air outlet. The results show that the room-air flow rate is close to $94.4 \mathrm{~L} / \mathrm{s}$, which is what the room-air fan provides at no load. 


\subsection{Experiment procedure}

The natural-gas flow rate and the exhaust-gas flow rate are the adjustable parameters for any setup. All experiments start with a low natural-gas flow rate and a low exhaust-gas flow rate; then the exhaust flow rate is adjusted by changing the voltage of the exhaust fan. A typical test run takes about 3 hours to finish where it usually takes about $1 \mathrm{hr}$ to reach steady-state conditions. The natural-gas flow rate is varied from $90 \%$ to $115 \%$ in increments of $10 \%$ and the last increment of $5 \%(100 \%$ corresponds to a flow rate of $0.33 \mathrm{~L} / \mathrm{s})$ while the exhaust-gas flow rate is altered by changing the voltage from 10 to $14 \mathrm{~V}$. The voltage applied on the exhaust fan is increased one volt every 30 min until it reaches $14 \mathrm{~V}$. For every experiment setting, the temperature data is plotted with time. The steady state data points are averaged to get the results for the test run.

Two test runs for Experiment 3 at $100 \%$ natural-gas flow rate were conducted: under induced and forced combustion air. For Experiment 2, the natural-gas flow rate was set at $100 \%$ for the single test run. For Experiment 1 , the natural-gas flow rate was set at $90 \%, 100 \%, 110 \%$, and $115 \%$ for varying exhaust-gas flow rates. Therefore, results from a total of 34 test runs were available distributed as 20 test runs for Experiment 1, 5 test runs for Experiment 2, and 9 test runs for Experiment 3.

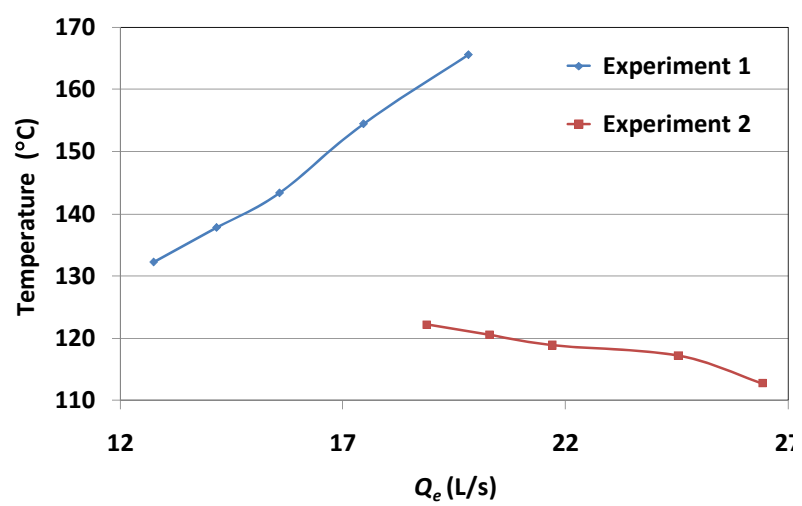

Figure 4: Firebox wall surface temperatures.

\section{Results and discussions}

The firebox wall surface temperature is essential to calculate the heat transfer from the firebox to the room air and to the tubes and fins. Fig. 4 shows results from experiments where the average firebox wall surface temperature begins to increase rapidly with increasing exhaust-gas flow rate for Experiment 1. However the average firebox wall temperature decreases with increasing exhaust-gas flow rate for Experiment 2. These results show the heating effect of the exhaust-gas by the firebox wall. An increasing exhaust-gas volumetric flow rate means that more excess air is used in the combustion. Hence, the increasing 
$Q_{e}$ lowers the exhaust-gas outlet temperature, as well as the firebox wall temperature. When there is exhaust gas passing through the tubes, it raises the tube temperature. At the exhaust-gas inlet, the exhaust-gas temperature is around $204^{\circ} \mathrm{C}$, which is above the average firebox wall temperature. Therefore, the outer tube surface might have a higher temperature than the firebox wall and radiates heat to the firebox wall or at least the tube receives less heat from the firebox wall. Even though the firebox wall temperature is not a constant, the difference is small compared with the temperature difference between the firebox wall and the air or the outer tube surface. Therefore, for simplicity, an average temperature of $146^{\circ} \mathrm{C}$ is chosen as the firebox wall surface temperature in the simulations for Experiment 1 and $118^{\circ} \mathrm{C}$ for Experiment 2.

\subsection{Isolated heat exchanger (experiment 3)}

During Experiment 3, it is expected that the heat loss of the exhaust gas be the same as the heat input to the room air $\left(q_{a}\right.$ should equal $\left.q_{e}\right)$. Rates of heat transfer shown in Fig. 5 are calculated based on Eqs. (1)-(4). These equations calculate the sensible heat as an "apparent" heat exchanged. Results presented here do not show this agreement which is due to the heat released by condensation process. Part of the heat released by condensation process is transferred to the room air, and part of the heat raises the exhaust-gas temperature.

The effect of induced and forced combustion air is shown in Fig. 5. The exhaust-gas and room-air inlet and outlet temperatures for the induced combustion air case are greater than those for the forced combustion air case. Also, the induced combustion has larger values for both $q_{a}$ and $q_{e}$. During the experiment, the induced combustion air case has a steady flame while the forced combustion air case has an unsteady flame and sometimes the flame quenches.

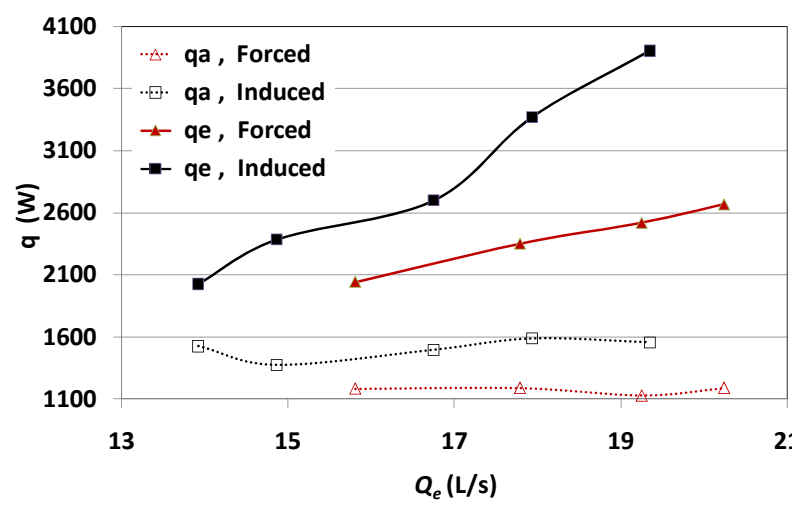

Figure 5: $\quad q_{a}$ and apparent $q_{e}$ for induced and forced combustion air flow of Experiment 1 .

When comparing the maximum temperature difference $\left(T_{e i}-T_{a i}\right)$ for both cases, the induced combustion air has an average maximum temperature difference of $178.3^{\circ} \mathrm{C}$, whereas the forced combustion air case has only 
$147.2^{\circ} \mathrm{C}$. Because the driving force for the forced combustion air case is about $15 \%$ lower than that for the induced combustion air case, the heat transfer rates for the exhaust gas and the room air of the forced combustion air case should be $15 \%$ less than that of the induced combustion air case. As shown in Fig. 5, the heat transfer differences between the two cases are in the vicinity of $15 \%$. After considering the uncertainty of the measurements (not reported here), this experiment shows that the induced and forced combustion air has no significant effect on the heat transfer.

\subsection{Cold exhaust gas (experiment 2)}

In the current setup, the exhaust gas does not pass through the heat exchanger. The combustion air is forced into the fireplace in this experiment, and the room air receives heat only from the firebox wall. The combustion-air flow rates of Experiment 2 were found higher than those for the same exhaust-gas fan voltage for Experiments 1 and 3 as shown in Fig. 6. This is because the exhaust fan does not have to overcome the pressure loss that the heat exchanger adds to the system. Because the exhaust-gas fan supplies more cold air to the fireplace, the flame temperature drops slightly for higher exhaust-gas flow rate. Therefore, the effect that this exhaust-gas flow rate difference in Experiment 2 has on to the heat transfer to the room air is neglected. Notice that, even though the exhaust gas is not passing through the heat exchanger, the temperature at the heat exchanger exhaust-gas inlet is higher than the room-air outlet temperature, which implies that the stagnant air inside the tubes is heated up by radiation from the firebox. Therefore, the heated tube surface serves as another heat source for heating up the room air. Comparing Experiments 1 and 2, the heat transfer to the room air for Experiment 1 is about 20 to 30 percent higher than that for Experiment 2, which means the heat transfer from the exhaust gas to the room air is of the same order of magnitude as the heat transfer from the firebox wall to the room air, but larger.

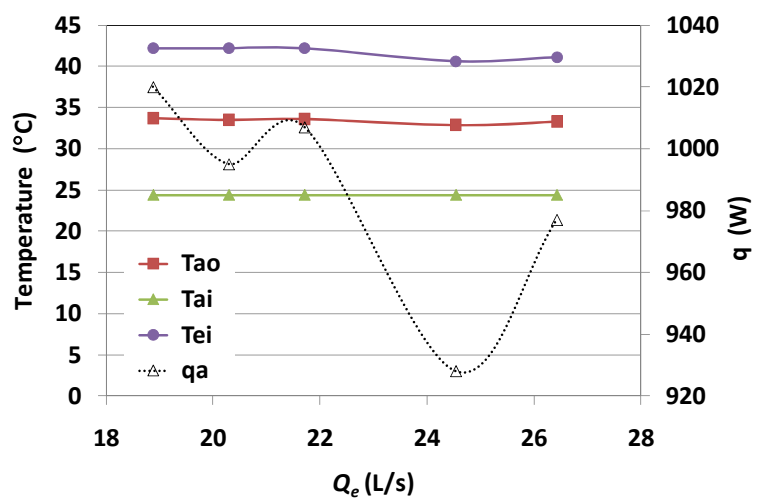

Figure 6: Effect of combustion gas flow rate on room and exhaust air temperatures and $q_{a}$ of experiment 2 . 


\subsection{Normal operating mode (experiment 1)}

The inlet and outlet temperatures and $Q_{e}$ are measured whereas the calculated $q_{a}$ and apparent $q_{e}$ are shown in Fig. 7. The room-air and exhaust-gas outlet temperatures are both increasing with increasing exhaust-gas flow rate for a constant natural-gas flow rate. An increasing room-air outlet temperature implies that increasing the exhaust-gas flow rate increases the heat transfer to the room air. The apparent heat extracted from the exhaust gas is increased with increasing exhaust-gas flow rate as well. When keeping the exhaust-gas flow rate constant, the outlet and inlet temperature differences are increasing with increasing natural-gas flow rate, which means increasing heat input to the heat exchanger. The heat transfer rates are increasing with increasing natural-gas flow rate because the increasing temperature difference increases the driving force.

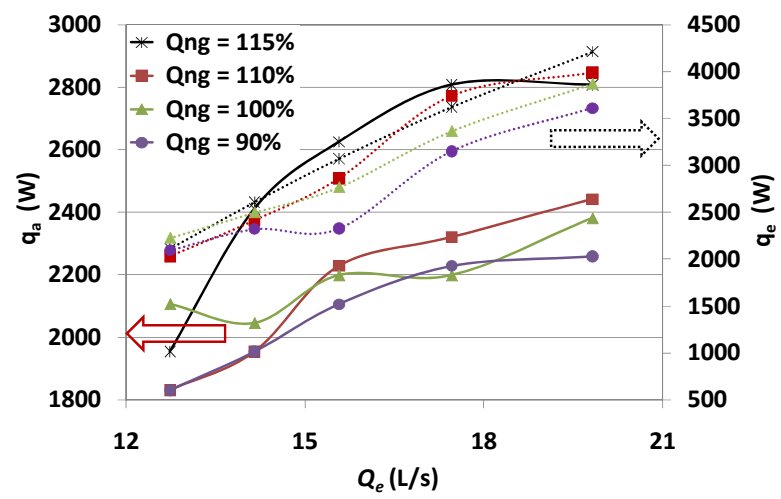

Figure 7: Effect of exhaust gas flow rate on the heat exchanged.

\subsection{Summary}

The three experiments are designed to test the different heat transfer modes to the room air, namely, Experiment 3 has only exhaust-gas heat transfer to the room air, Experiment 2 has only firebox wall heat transfer to the room air, and Experiment 1 combines the two contributions. With the assumption that the exhaust-gas flow rate does not affect the heat transfer from the firebox wall to the room air, the heat transfer rate to the room air of Experiment 1 should be approximately the sum of that of Experiments 2 and 3, even thought the exhaust gas flow rate of Experiment 2 is not the same as that of Experiments 1 and 3. The values for the heat transfer to the room air in Fig. 8 show that the heat transfer rate for Experiment 1 is not exactly the summation of those for Experiments 2 and 3. The presence of the exhaust gas inside the tubes in Experiment 1 decreases the heat transfer from the firebox wall. The tube wall temperature for Experiment 2 is almost constant compared to that of Experiment 1 , which varies greatly from close to the exhaust gas inlet temperature to near the exhaust-gas dew point temperature. Because no exhaust gas flows through the 
tubes, the air temperature inside the tube is very close to the temperature of the tube wall. Therefore, the tube wall temperature for Experiment 2 is close to the dew point temperature of the exhaust gas over the heat exchanger. On the other hand, in Experiment 1, the tube wall temperature is much higher than the dew point temperature when the exhaust gas temperature is high. Only after about two passes, the tube wall temperature drops close to the dew point temperature. Therefore, in Experiment 2, the tube wall is receiving much more radiation from the firebox wall than in Experiment 1, because of the much lower average tube surface temperature.

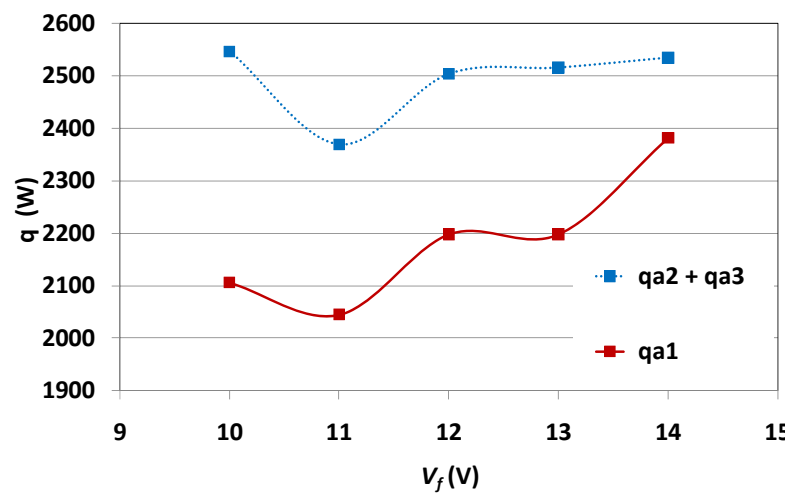

Figure 8: Heat transfer to room air contributions.

\section{Conclusion}

The waste heat recovery in supplemental heaters was experimentally studied using an in-house heat exchanger prototype, in different conditions. It was shown that the heat exchanger can significantly reduces the fuel consumption. The experiments also indicate that condensation occurs within the exhaust-gas tubes. Future work is recommended to pursue further quantification of the condensate production as related to waste heat recovery. The treatment and management of condensate as a challenge to the design and construction of the proposed heat exchanger design for waste heat recovery is also of importance for future development of such heat exchangers.

\section{Acknowledgements}

The authors would like to acknowledge the financial support received from Prince Mohammad Bin Fahd University (PMU) to cover the cost of attending this conference. Furthermore, the authors wish to acknowledge the Iowa Energy Center and HNI Corporation for their support and interest in this project. The information and assistance provided by them is much appreciated. The authors also express their thanks to Mat Pierce of HNI Corporation who participated in conducting most of the experiments and provided valuable lab assistance. 


\section{References}

[1] G. F. Hessler, Issues in heat recovery steam generator system noise, The Journal of the Acoustical Society of America, 101 (1997) 3038-3038.

[2] A. Mihelic-Bodanic, R. Budin, Heat recovery in thermoplastics production, Energy Conversion and Management, 43 (2002) 1079-1089.

[3] D. V. Maksimov, N. N. Kochanov, N. N. Mittsenko, Z. V. Zagryadskaya, V. E. Grinberg, Experience in introduction of heat recovery systems, Chemistry and Technology of Fuels and Oils, 36 (2000) 308-309.

[4] M. Fehrm, W. Reiners, M. Ungemach, Exhaust air heat recovery in buildings, International Journal of Refrigeration, 25 (2002) 439-449.

[5] R. Tugrul Ogulata, Utilization of waste-heat recovery in textile drying, Applied Energy, 79 (2004) 41-49.

[6] F. Yang, X. Yuan, G. Lin, Waste heat recovery using heat pipe heat exchanger for heating automobile using exhaust gas, Applied Thermal Engineering, 23 (2003) 367-372.

[7] M. De Monte, E. Padoano, D. Pozzetto, Waste heat recovery in a coffee roasting plant, Applied Thermal Engineering, 23 (2003) 1033-1044.

[8] L. Junhong, L. Zhizhang, G. Jianming, L. Zhiwei, Truck waste heat recovery, Applied Thermal Engineering, 23 (2003) 409-416.

[9] F. Pettersson, J. Soderman, Design of robust heat recovery systems in paper machines, Chemical Engineering and Processing: Process Intensification, 46 (2007) 910-917.

[10] Y. Naganuma, Multifunctional heat recovery-type coal gasification systems, Fuel and Energy Abstracts, 39 (1998) 188.

[11] D. R. Rousse, D. Y. Martin, R. Theriault, F. Leveillee, R. Boily, Heat recovery in greenhouses: a practical solution, Applied Thermal Engineering, 20 (2000) 687-706.

[12] E. Goto, S. Kase, H. Ding, Exhaust Heat Recovery in Internal Combustion Engine, JSAE Review, 16 (1995) 313-314.

[13] J. S. Cain, Heat recovery apparatus for use with a non-high efficiency furnace, Applied Thermal Engineering, 16 (1996) 9.

[14] R. Yang, P. Wang, The effect of heat recovery on the performance of a glazed solar collector/regenerator, Solar Energy, 54 (1995) 19-24.

[15] M. S. Soylemez, On the optimum heat exchanger sizing for heat recovery, Energy Conversion and Management, 41 (2000) 1419-1427.

[16] E. Y. Tanbour, J. Hu, T. F. Smith, Waste heat recovery heat exchanger for supplemental heaters, Technical Report, University of Iowa, Report No. ME-TFS-01-006, 2001.

[17] F. P. Incropera, D. P., DeWitt, Fundamentals of Heat and Mass Transfer, 4th ed., John Wiley \& Sons, New York, New York, 1996. 